\title{
European Green Deal: a major opportunity for health improvement
}

Andy Haines ${ }^{1}$ and Pauline Scheelbeek ${ }^{2}$

1) Professor of Environmental Change and Public Health, Centre for Climate Change and Planetary Health, London School of Hygiene and Tropical Medicine; 2) Assistant Professor in Nutritional and Environmental Epidemiology, Centre for Climate Change and Planetary Health, London School of Hygiene and Tropical Medicine

The European Green Deal[1], announced just before Christmas, aims to respond to the escalating climate crisis by achieving net zero greenhouse gas (GHG) emissions from the EU by 2050. The proposal also aspires to 'protect the health and well-being of citizens from environment-related risks and impacts'. Current policies will only achieve $60 \%$ reductions by 2050 , indicating the need for increased ambition. Figure 1 outlines the ambitious scope of the Green Deal that also aims to establish a toxic-free environment, deliver healthy and sustainable diets, and protect biodiversity. It therefore encompasses a potentially ambitious agenda to support Planetary Health[2].

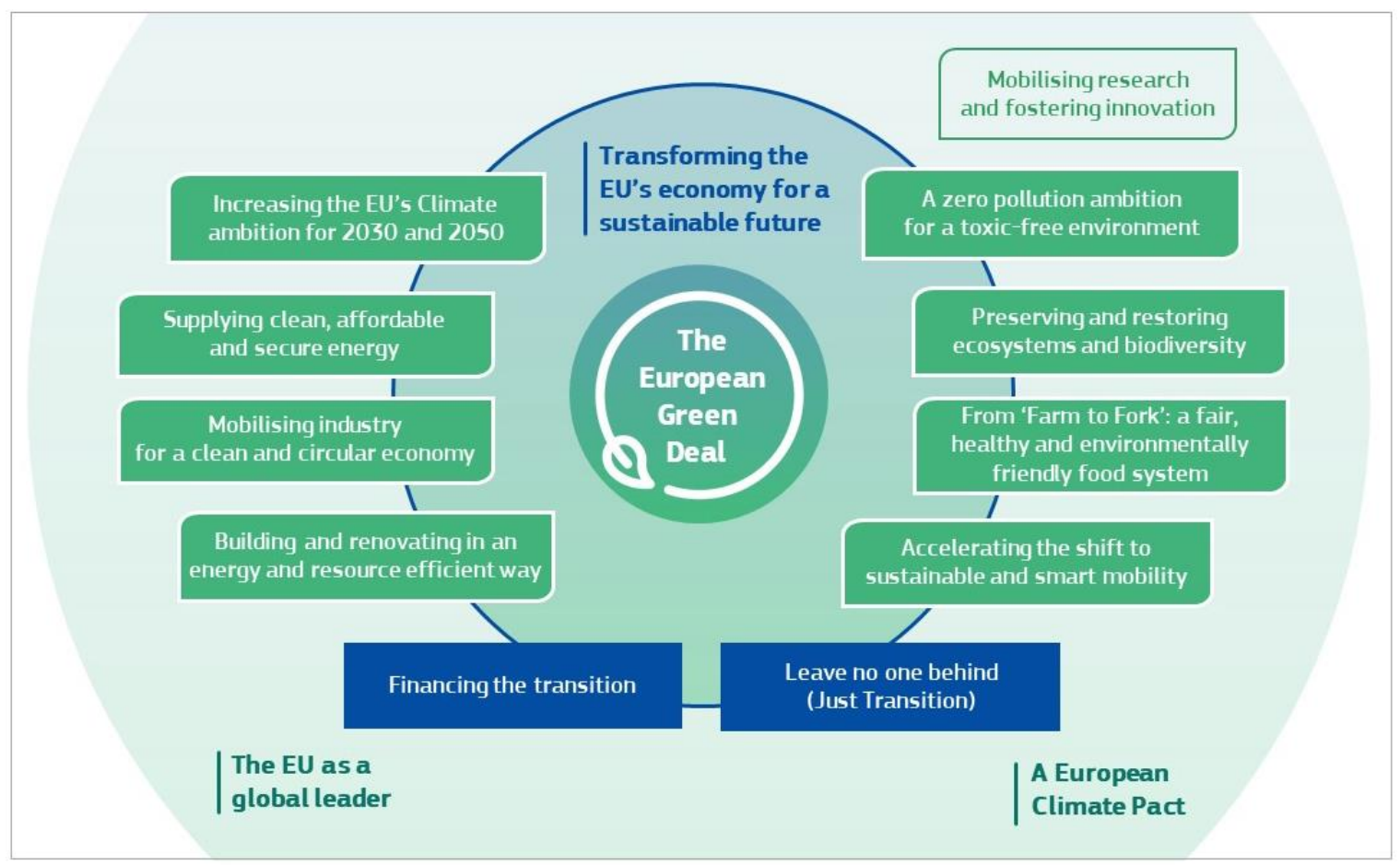

Figure 1: The European Green Deal

Europe alone cannot ensure that the global mean temperature increase is kept to $<2^{\circ} \mathrm{C}$ above preindustrial levels as laid out in the Paris Climate Agreement[3], but the EU's intention is to play a leadership role by cutting its own emissions rapidly and using its financial resources, knowledge and influence to encourage other nations to increase their climate actions. The Commission emphasizes the importance of reducing the likelihood of GHG 'leakage' (i.e. more carbon-intensive imports to replace EU-products from countries with lower ambitions for GHG-emission reduction), by ensuring that import prices reflect carbon footprints.

Many details of the proposed Green Deal remain to be worked out but there can be no doubt that it has the potential to achieve major health improvements in the near-term, whilst reducing the growing health risks from climate change[4].

The near-term health benefits can arise through successful policy implementation in sectors that substantially contribute to emissions of $\mathrm{CO}_{2}$ and short-lived climate pollutants (e.g. methane and black 
carbon), such as the energy, housing, transport, food, industry and health care sectors[5]. Successful policies would reduce GHGs, fine particulate air pollution and tropospheric ozone with major benefits to health. Replacing fossil fuels by clean renewable energy across these sectors could prevent 3.6 million premature deaths annually worldwide (at 2015 population) from ischaemic heart disease (IHD), stroke, chronic obstructive pulmonary disease and other causes, with about 430,000 of these being in the EU[6]. When prevented deaths are valued using a standard economic approach (Value of a Statistical Life[7]) economic benefits of reduced mortality substantially offset the costs of scaling up renewable energy.

Major health benefits also arise from transport strategies to promote active travel (i.e. walking and cycling) together with greater use of public transport. For example, one study suggested that if the urban population of England and Wales walked and cycled as much as their Copenhagen counterparts there would be substantial reductions in incidence of diabetes, IHD, stroke and other conditions related to sedentary lifestyle that could result in $£ 17 \mathrm{bn}$ costs averted to the NHS over a 20-year period[8]. Health benefits occur particularly from encouraging sedentary middle-aged and older people to walk and cycle. Accessibility to suitable sustainable transport options would be crucial: for example, electric bicycles could increase the likelihood of continuing to cycle into older age. The health benefits of increased active travel are likely to greatly exceed the adverse effects of increases in injury risk[9] which in turn can be reduced through policies to improve road safety.

Provision of green space in urban areas can influence health in multiple ways. For example, green space exposure within a five-minute walk of the home $(\sim 300 \mathrm{~m})$ would stimulate its use: several studies report on reductions in NCD-risk and improved mental health for those living within close proximity of green space (e.g.[10]). Green space can also reduce urban heat islands and associated ill health, as well as reduce further energy requirements for cooling. Nature-based solutions can also have benefits for climate change adaptation including flood control and watershed protection as well as protecting biodiversity[2] but potential unintended consequences such as increases in vector-borne disease transmission must be anticipated and addressed.

Energy-efficient housing, including through retrofitting programmes to insulate existing houses and shutters to shade windows, can reduce cold and heat exposure respectively and improve health, providing that build-up of household air pollutants including radon, tobacco smoke and pollutants from cooking is averted by adequate ventilation[11].

The "Farm to Fork Strategy" is an important component of the Green Deal and specifically addresses EU food system sustainability. Besides the positive health impacts of reduced emissions and pollution by cleaner and more sustainable production and processing of food, the strategy aims to actively engage the consumer, by encouraging dietary shifts towards more sustainable foods including vegetables, fruit, whole grains, nuts and seeds, and reduced consumption of red and processed meat. Health benefits include reduced obesity prevalence, and reduced risk of NCDs such as IHD and stroke [12]. A UK modelling study found that a reduction in dietary GHG emissions of $17 \%$ (by switching from "current" to WHO-recommended diets) was associated with an average increase of life expectancy by $\sim 8$ months[13]. Further dietary changes resulting in emission reductions (up to $\sim 40 \%$ ) may be achievable, but larger reductions may be limited by acceptability.

Health care is responsible for $\sim 5 \%$ of GHG emissions but its importance may be greater: health professionals have potentially large impacts on social attitudes towards decarbonization and behavioral change. Procurement policies for zero-carbon energy and reducing the environmental impact of pharmaceuticals and medical equipment can promote decarbonization[14]. 
Besides production-related emissions, consumption-related emissions must be addressed to achieve climate targets. The Green Deal advocates for rapid movement towards a circular economy based on recycling, re-use, remanufacturing and shared use. In order to avoid increased exposure to toxic chemicals from these processes, health risks must be minimized by better regulations and their implementation[15].

Overall there are major health and environmental benefits to be had from implementation of the Green Deal but capitalizing on their potential will require careful design and evaluation of policy choices. A systematic assessment should be undertaken of the health implications and GHG emission reductions from different sectoral mitigation strategies for EU-countries as well ask careful assessment of all potential unintended negative consequences for health, environment and economy. Successful implementation of the Green Deal also has important implications for other countries that will be looking carefully at EU-experience.

\section{References}

1. European Commission. A European Green Deal: Striving to be the first climate-neutral continent. 2019 [cited 2020 03-01]; Available from:

https://ec.europa.eu/info/strategy/priorities-2019-2024/european-green-deal en.

2. Whitmee, S., et al., Safeguarding human health in the Anthropocene epoch: report of The Rockefeller Foundation-Lancet Commission on planetary health. The Lancet, 2015. 386(10007): p. 1973-2028.

3. United Nations, Paris Agreement. 2015.

4. Haines, A. and K. Ebi, The imperative for climate action to protect health. New England Journal of Medicine, 2019. 380(3): p. 263-273.

5. Haines, A., et al., Public health benefits of strategies to reduce greenhouse-gas emissions: overview and implications for policy makers. The Lancet, 2009. 374(9707): p. 2104-2114.

6. Lelieveld, J., et al., Effects of fossil fuel and total anthropogenic emission removal on public health and climate. Proceedings of the National Academy of Sciences, 2019. 116(15): p. 71927197.

7. Markandya, A., et al., Health co-benefits from air pollution and mitigation costs of the Paris Agreement: a modelling study. The Lancet Planetary Health, 2018. 2(3): p. e126-e133.

8. Jarrett, J., et al., Effect of increasing active travel in urban England and Wales on costs to the National Health Service. The Lancet, 2012. 379(9832): p. 2198-2205.

9. Mueller, N., et al., Health impact assessment of active transportation: a systematic review. Preventive medicine, 2015. 76: p. 103-114.

10. Sugiyama, T., et al., Associations of neighbourhood greenness with physical and mental health: do walking, social coherence and local social interaction explain the relationships? Journal of Epidemiology \& Community Health, 2008. 62(5): p. e9-e9.

11. Wilkinson, P., et al., Public health benefits of strategies to reduce greenhouse-gas emissions: household energy. The Lancet, 2009. 374(9705): p. 1917-1929.

12. Willett, W., et al., Food in the Anthropocene: the EAT-Lancet Commission on healthy diets from sustainable food systems. The Lancet, 2019. 393(10170): p. 447-492.

13. Milner, J., et al., Health effects of adopting low greenhouse gas emission diets in the UK. BMJ open, 2015. 5(4): p. e007364.

14. Health Care Without Harm and Arup, Health Care's Climate Footprint. How the health sector contributes to the global climate crisis and opportunities for action. 2019.

15. Organization, W.H., Circular Economy and Health: Opportunities and Risks. World Health Organization Regional Office for Europe: Copenhagen, Denmark, 2018. 